\title{
Association between frailty and delirium in older adult patients discharged from hospital
}

This article was published in the following Dove Press journal:

Clinical Interventions in Aging

18 January 2016

Number of times this article has been viewed

\author{
Henk Verloo' \\ Céline Goulet ${ }^{2}$ \\ Diane Morin ${ }^{3,4}$ \\ Armin von Gunten ${ }^{5}$ \\ 'Department Nursing Sciences, \\ University of Applied Sciences, \\ Lausanne, Switzerland; ${ }^{2}$ Faculty \\ of Nursing Science, University of \\ Montreal, Montreal, QC, Canada; \\ ${ }^{3}$ Institut Universitaire de Formation \\ et Recherche en Soins (IUFRS), \\ Faculty of Biology and Medicine, \\ University of Lausanne, Lausanne \\ University Hospital, Lausanne, \\ Switzerland; ${ }^{4}$ Faculty of Nursing \\ Science, Université Laval, Québec, \\ Canada; ${ }^{5}$ Department of Psychiatry, \\ Service Universitaire de Psychiatrie \\ de l'Age Avancé (SUPAA), Lausanne \\ University Hospital, Prilly, Switzerland
}

Correspondence: Henk Verloo University of Applied Nursing Sciences, La Source, 30, Avenue Vinet, $\mathrm{CH}-\mathrm{I} 004$ Lausanne, Switzerland Tel +4I 2I 64I 3867

Fax +4I 21 64I 38I0

Email h.verloo@ecolelasource.ch
Background: Delirium and frailty - both potentially reversible geriatric syndromes - are seldom studied together, although they often occur jointly in older patients discharged from hospitals. This study aimed to explore the relationship between delirium and frailty in older adults discharged from hospitals.

Methods: Of the 221 patients aged $>65$ years, who were invited to participate, only 114 gave their consent to participate in this study. Delirium was assessed using the confusion assessment method, in which patients were classified dichotomously as delirious or nondelirious according to its algorithm. Frailty was assessed using the Edmonton Frailty Scale, which classifies patients dichotomously as frail or nonfrail. In addition to the sociodemographic characteristics, covariates such as scores from the Mini-Mental State Examination, Instrumental Activities of Daily Living scale, and Cumulative Illness Rating Scale for Geriatrics and details regarding polymedication were collected. A multidimensional linear regression model was used for analysis.

Results: Almost $20 \%$ of participants had delirium ( $n=22)$, and $76.3 \%$ were classified as frail $(\mathrm{n}=87) ; 31.5 \%$ of the variance in the delirium score was explained by frailty $\left(R^{2}=0.315\right)$. Age; polymedication; scores of the Confusion Assessment Method (CAM), instrumental activities of daily living, and Cumulative Illness Rating Scale for Geriatrics; and frailty increased the predictability of the variance of delirium by $32 \%$ to $64 \%\left(R^{2}=0.64\right)$.

Conclusion: Frailty is strongly related to delirium in older patients after discharge from the hospital.

Keywords: Edmonton Frailty Scale, delirium risk factors, cognitive impairment, physical impairment

\section{Introduction}

Delirium is a mental disorder with an acute onset and fluctuating course, characterized by disturbances of consciousness, orientation, memory, thought, perception, and behavior. ${ }^{1}$ This syndrome represents a serious problem in acute care hospitals and is associated with decreased functional status, longer periods of time before recovery and discharge, institutionalization, premature mortality, and increased health care costs. The etiology of delirium is considered to be multifactorial, with an occurrence rate as high as $83 \%$ in hospitals. ${ }^{2}$ Multicomponent delirium prevention strategies have been shown in intervention studies to consistently reduce the occurrence of delirium. ${ }^{3}$ Based on this evidence base, the National Institute for Health and Care Excellence has advocated the adoption of multicomponent delirium prevention interventions into the routine care for older inpatients. ${ }^{4}$ However, despite successful reductions in incident delirium by about a third, anticipated reductions in mortality or admissions to longterm care have not been conclusively observed. ${ }^{5}$ One-third of older patients still have undetected and unresolved symptoms of delirium at hospital discharge. ${ }^{6}$ 
Frailty is a geriatric condition characterized by diminished strength, endurance, and physiological functions that increase an individual's vulnerability to adverse outcomes such as falls, sarcopenia, institutionalization, worsened disability, and premature death. ${ }^{7}$ Frailty was recently defined as a state of increased vulnerability related to a poor level of homeostasis after a stressful event, with a corresponding increased risk of adverse outcomes, including falls, delirium, and disability. ${ }^{7}$ Frailty has been linked to the development and progression of many age-related diseases and syndromes. ${ }^{8}$

However, little is known about the relationship of frailty as a precipitating risk factor for specific geriatric syndromes in hospitalized older patients. ${ }^{9}$ Frailty associated with hospitalization may occur in one-third of older patients and can be triggered even when the illness causing hospitalization is successfully treated. ${ }^{7}$ Frailty has a considerable influence not only on outpatients' independence and quality of life but also on their use of health care services. ${ }^{10}$

Delirium and frailty appear to be distinct clinical geriatric conditions. However, in vulnerable older adults, both syndromes can appear simultaneously in response to a stressor. ${ }^{9}$ Besides the elevated rates of delirium during hospitalization, studies have reported about the important consequences of frailty among older adults discharged from hospital, including increased dependence as shown on the Instrumental Activities of Daily Living (IADL) scale, weight loss, and cognitive impairment. ${ }^{11}$ These consequences result from the acute syndrome of delirium itself and are also related to the management of patient care during hospitalization. They can lead to a state of severe frailty at discharge, with a high risk of premature death. ${ }^{12}$

Delirium has been associated with increased long-term cognitive impairment and acceleration of existing cognitive decline. Furthermore, it may delay physical and cognitive recovery, ultimately resulting in new or increasing frailty and long-term disability and institutionalization. Both frailty and delirium in older patients can affect independent functioning and the ability to live at home. ${ }^{9}$ A study on older patients who had undergone cardiac surgery and then developed postoperative delirium showed that delirium was associated with an approximately twofold increase in the risk of frailty after 1 month. ${ }^{13}$ However, few studies have examined the relationship between frailty and delirium among older patients. ${ }^{14,15}$

Therefore, we hypothesized that delirium and frailty were associated in a sample of older adult patients discharged from a hospital.

\section{Methods and materials}

Data were sourced from a prospective clinical trial entitled "Effect estimation of an innovative nursing intervention to improve delirium among home-dwelling older adults," which was conducted in 2012 and published elsewhere. ${ }^{16}$ The trial protocol was approved by the cantonal medical ethics committee of Valais, Switzerland (CCVEM 030/11). Written informed consent was obtained from all participants or from their closest relatives if they scored $<15$ points on the Mini-Mental State Examination (MMSE). ${ }^{17}$

\section{Participants}

In the original study, a nonprobabilistic sample of 221 eligible participants was contacted within 48 hours of their hospital discharge, in collaboration with a home health care service, in order to request their participation. For different reasons, 107 older adults refused to participate, resulting in a final sample of 114 participants. Patients with a medical prescription for home health care were eligible to participate if they were 1) aged 65 years or older, 2) discharged after hospitalization of at least $\geq 48$ hours, and 3 ) capable of understanding and answering questions in French. Figure 1 presents the recruitment procedure.

\section{Measurements}

\section{Assessment of delirium}

Delirium was assessed using the validated French version of the Confusion Assessment Method (CAM). ${ }^{18}$ The CAM is an instrument developed to assist clinicians in identifying patients with delirium. It has been considered suitable for bedside use. ${ }^{19}$ The psychometric properties of the CAM have been documented as excellent, with 94\% sensitivity, $89 \%$ specificity, and a Kappa's inter-rater reliability between 0.70 and $1.00 .{ }^{19}$ The research nurse or the principal investigator (PI) completed the CAM form based on a structured interview, patient records, and clinical observation of the symptoms/signs described in the CAM. Data were subsequently analyzed categorically by using the CAM algorithm. The inter-rater reliability between the PI and the research nurse (trained in CAM assessment) showed a satisfactory Kappa Cohen's coefficient of $0.79 .{ }^{20}$

\section{Assessment of frailty}

The frailty status was assessed using the Edmonton Frailty Score (EFS) developed by Rolfson et $\mathrm{al}^{21}$ and been evaluated in a systematic review of de Vries et al. ${ }^{22}$ This instrument consists of nine domains and eleven items, each scoring 0 points (frailty absent or normal health), 1 point (minor errors or mild/moderate impairment), or 2 points (important errors or severely impaired). The domains include cognitive impairment, autoevaluation of general health status, functional dependency, presence of social support, drug treatments and 
Adults ( $\geq 18$ years) requesting health care from a home health care center between February 2012 and October $2012(n=319)$
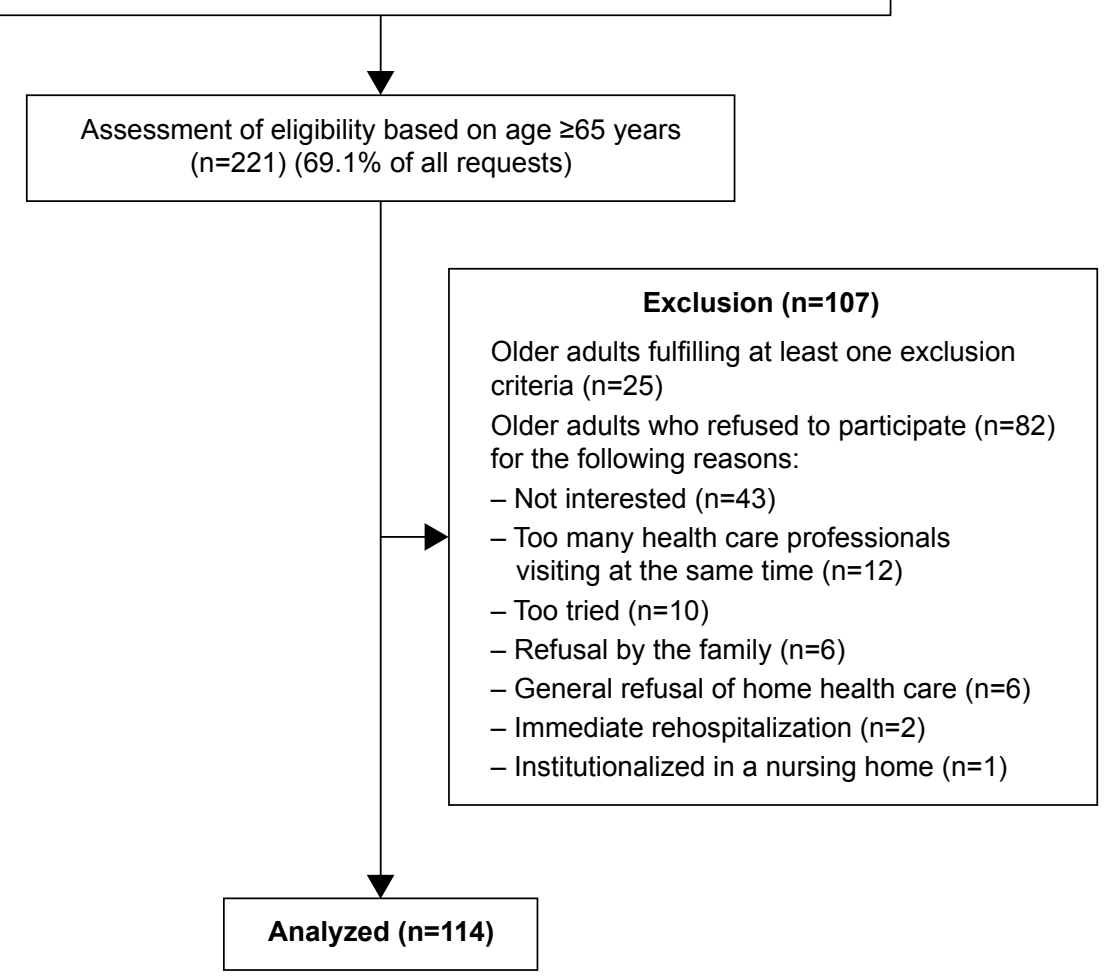

Figure I Recruitment of the participants.

adherence, nutrition and mood, presence of incontinence, and the "timed up and go (TUG)" test. The TUG tests the basic mobility skills of frail elderly persons. It consists of a measurement of the time in seconds for a person to rise from sitting from a standard arm chair, walk $3 \mathrm{~m}$, turn, walk back to the chair, and sit down. A cutoff score of $\geq 20$ seconds was shown to predict falls in community-dwelling frail elderly people. ${ }^{23}$

The total score from 0 to 3 points indicates no frailty; 4 or 5 points indicate prefrailty; 6 to 8 points indicates frailty; and 9 to 17 points indicates severe frailty. In order to dichotomize between frail and not frail, a score of 6 points or more was considered as frail. The eleven-item EFS has good psychometric properties and showed an acceptable Cronbach's alpha of 0.62 in the present study. ${ }^{21}$ The inter-rater reliability between the PI and the research nurse was excellent (Kappa Cohen's coefficient $=0.85$ ).

\section{Other variables}

Sociodemographic characteristics assessed included age, sex, marital status, and level of education (Table 1).

Cognitive level was assessed using the MMSE by regrouping the seven domains of cognitive functioning. ${ }^{17,24}$ The eleven-item instrument measures orientation, memory, language, and psychomotor skills. The sum of the scores varies from 0 (severe cognitive impairment) to 30 (no cognitive impairment). A score of $<24$ points was considered as the cutoff point for cognitive impairment. The MMSE was mostly assessed by the PI, and the instrument presents good psychometric proprieties. ${ }^{25}$ An excellent inter-rater ratio was obtained between the PI and the research nurse with an intraclass correlation of 0.92 .

Table I Sociodemographic characteristics of participants $(n=|| 4)$

\begin{tabular}{ll}
\hline Variables & \\
\hline Age (years) & \\
$\quad$ Average (SD) & \\
Sex & $74.2(7.2)$ \\
$\quad$ Female (\%) & \\
Marital status & $7(6.9)$ \\
Single (\%) & 41 (36.0) \\
Married/partner (\%) & $6(5.3)$ \\
Divorced/separated (\%) & $60(52.6)$ \\
Widowed (\%) & \\
Education & $13(12.5)$ \\
Primary (\%) & $38(36.5)$ \\
Secondary (\%) & $33(31.7)$ \\
Vocational (\%) & $20(19.2)$ \\
University (\%)
\end{tabular}

Abbreviation: SD, standard deviation. 
Table 2 Health status of participating delirious and nondelirious discharged older adults

\begin{tabular}{|c|c|c|c|}
\hline Variables & No delirium $(n=20)$ & Delirium $(n=94)$ & $P$-value \\
\hline \multicolumn{4}{|l|}{ Sex } \\
\hline Male/female $(n=\mid 14)$ & $32 / 62$ & $8 / 12$ & $0.612^{\mathrm{b}}$ \\
\hline \multicolumn{4}{|l|}{ Age } \\
\hline Average (SD) & $83.2(7.2)$ & $83.5(7.2)$ & $0.875^{c}$ \\
\hline \multicolumn{4}{|l|}{ Edmonton Frailty Scale (EFS) } \\
\hline Average (SD) & $7.96(2.6)$ & $10.05(3.3)$ & $<0.00 \mathrm{I}^{\mathrm{c}, *}$ \\
\hline Range & $1-17$ & $1-17$ & \\
\hline \multicolumn{4}{|l|}{ Frail vs not fraild } \\
\hline Frail (\%) & 71 (75.5) & $18(90.0)$ & $0.235^{\mathrm{e}}$ \\
\hline Not frail (\%) & $23(24.5)$ & $2(10.0)$ & \\
\hline \multicolumn{4}{|l|}{ Health status } \\
\hline Cognitive impairment, MMSE (SD) & $24.57(4.3)$ & $19.20(5.4)$ & $<0.00 \mathrm{I}^{\mathrm{c}, *}$ \\
\hline Functional status, IADL (SD) & $20.59(5.6)$ & $23.70(6.0)$ & $0.029^{c, *}$ \\
\hline Comorbidities, CIRS-G (SD) & I3.68 (3.2) & $14.25(2.5)$ & $0.458^{c}$ \\
\hline Average no daily medications (SD) & $6.30(3.1)$ & $6.30(2.6)$ & $0.997^{c}$ \\
\hline
\end{tabular}

Notes: 'Pearson's chi-squared test. 'Student's $t$-test. 'Based on EFS, frail $\geq 6$ points. eFisher's exact test. *Significance $P \leq 0.05$.

Abbreviations: SD, standard deviation; MMSE, Mini-Mental State Examination; IADL, Instrumental Activities of Daily Living; CIRS-G, Cumulative IIIness Rating Scale for Geriatrics.

Functional status was assessed using the Lawton Index of IADL, an assessment considered appropriate for older adults living at home. ${ }^{26,27}$ The IADL scale assesses independence versus dependence in more complex areas of daily living, such as using the telephone, shopping, preparing meals, cleaning and laundry, using public transport, management of medication and finances, and maintaining a home. ${ }^{28}$ A score of $<16$ indicates that the patient is independent, as documented elsewhere. ${ }^{28}$ Inter-rater reliability was excellent (Kappa Cohen's coefficient $=0.85$ ). Finally, comorbidities were assessed using the Cumulative Illness Rating Scale for Geriatrics (CIRS-G). The CIRS-G scores diseases in 13 organ systems and grades each organ according to severity using explicit rules for classification. Data for CIRS-G scoring were compiled from comprehensive patient interview and chart records. A CIRS-G index of comorbidity of $\geq 2$ implies the presence of moderate and severe illnesses. ${ }^{29}$ Inter-rater scores between the PI and the research nurse were very high (Pearson's correlation $=0.81$ ). The number of prescribed medications was recorded during patient interviews and through patient records. Participants' health status and average medication use are presented in Table 2.

\section{Data collection}

After the participants had given their consent, data were collected during a single home visit within 48 hours of discharge from the hospital. During the home visits, the data collection procedure was standardized to avoid any bias by using an invariable sequence of questions. Data on delirium, frailty, cognition, health status, comorbidities, and medication treatment were collected immediately after consent of the patients at their place they live. It is important to mention that during hospitalization and at hospital discharge, no delirium of frailty assessment was done. A detailed description of the data collection procedure has been published elsewhere. ${ }^{16}$

\section{Statistical analyses}

Sociodemographic and baseline characteristics of subjects with and without frailty were compared using the Student's $t$-test for continuous variables and a chi-squared distribution for categorical ones. The odds ratio (OR) of delirium/frailty was calculated using a contingency table in a joint frequency distribution. The association between delirium and frailty was assessed using linear regression, and this association was adjusted for age, cognitive state (MMSE), physical state (IADL), chronic conditions reported (CIRS-G), and polymedication. Collinearity was verified using a matrix correlation and tolerance values. ${ }^{30}$ All statistical tests were performed using the IBM-Statistical Package for the Social Sciences (IBM-SPSS ${ }^{\circledR}$ ), Version 22. ${ }^{31}$ Statistical significance was set at $P=0.05$, and all tests were two tailed.

\section{Results}

\section{Participant characteristics}

No statistically significant differences were found between men and women with regard to being nondelirious or delirious $(P=0.612)$ and their ages $(P=0.875$; Table 2$)$. Similarly, there were no statistically significant differences with regard to being frail and nonfrail $(P=0.560)$ and their ages $(P=0.742$; Table 3). 
Table 3 Health status among frail and nonfrail discharged older adults

\begin{tabular}{|c|c|c|c|}
\hline Variables & Not fraila $(n=25)$ & Frail $^{a}(n=89)$ & $P$-value \\
\hline \multicolumn{4}{|l|}{ Sex } \\
\hline Men/women & $10 / 15$ & $30 / 59$ & $0.560^{\mathrm{b}}$ \\
\hline \multicolumn{4}{|l|}{ Age (SD) } \\
\hline Average (SD) & $82.80(8.3)$ & $83.34(6.9)$ & $0.742^{\mathrm{c}}$ \\
\hline \multicolumn{4}{|l|}{ Health status } \\
\hline Cognitive impairment, MMSE (SD) & $26.28(3.5)$ & $22.89(5.0)$ & $0.002^{\mathrm{c}, *}$ \\
\hline Functional status, IADL (SD) & $16.64(4.7)$ & $22.39(5.5)$ & $<0.000^{\mathrm{c}, *}$ \\
\hline Comorbidities, CIRS-G (SD) & $11.36(3.6)$ & $14.46(2.6)$ & $<0.000^{c, *}$ \\
\hline Average number daily medications (SD) & $5.20(2.4)$ & $6.61(2.7)$ & $0.019^{c, *}$ \\
\hline
\end{tabular}

Notes: aBased on EFS, frail $\geq 6$ points. 'Pearson's chi-squared test. 'Student's $t$-test. *Significance $P \leq 0.05$.

Abbreviations: SD, standard deviation; MMSE, Mini-Mental State Examination; IADL, Instrumental Activities of Daily Living; CIRS-G, Cumulative IIIness Rating Scale for Geriatrics; EFS, Edmonton Frailty Scale.

\section{Prevalence of delirium and frailty}

Almost one-fifth of the sample $(n=20)$ presented with delirium as measured by the CAM. Almost two-thirds of the frail older adults presented with three or more symptoms of delirium (Table 2). Three quarters of participants $(n=89)$ presented with frailty, including $90 \%$ of the delirious participants $(n=18)$. The mean frailty score for nondelirious participants was significantly lower than that for delirious participants $(P<0.001$; Table 2$)$.

Measurements of IADL at hospital discharge showed statistically significant differences in dependency: nonfrail participants were less dependent than frail ones $(P<0.001)$, and nondelirious participants were less dependent than delirious ones $(P=0.029)$. Similar statistical differences were observed. With regard to cognitive status, nonfrail participants had a better cognitive status than frail ones $(P=0.002)$, and nondelirious participants had a better cognitive status than delirious ones $(P \leq 0.001)$. Most of the participants had comorbidities and were being prescribed more than four medications. A significant difference was observed in the comorbidity rates and the average number of medications of frail and nonfrail participants $(P=0.019)$, but the difference was not significant between nondelirious and delirious participants ( $P=0.997$; Tables 2 and 3$)$.

The high prevalence of frailty among delirious participants reflects the fact that in four of the eleven EFS items - namely cognitive impairment, medication adherence problems, incontinence, and the "timed up and go" test - the scores significantly increased in delirious participants compared to nondelirious participants ( $P \leq 0.001, P=0.018, P=0.004$, and $P=0.041$, respectively; Table 4).

\section{Association between frailty and delirium}

The OR of delirium/frailty indicated that frailty was 1.19 times more present (statistically significant) among participants with delirium than among participants without delirium, with a $95 \%$ confidence interval $(95 \% \mathrm{CI})$ of 1.00-1.43. Cognitive status (MMSE) seemed to be a stronger risk factor for delirium than frailty, with an OR of 4.31 (95\% CI [1.51-12.28]). Neither IADL (OR 1.13; 95\% CI [0.91-1.41]), age (OR 1.12; 95\% CI [0.43-2.96]), and CIRS-G (OR 1.04; 95\% CI (0.58-1.89]) nor polymedication (OR 1.03; 95\% CI [0.34-3.14]) were significant risk factors for delirium.

Linear regression indicated that $32 \%$ of the variance in delirium was explained by frailty alone $\left(R^{2}=0.315 ; P<0.001\right)$, thus suggesting that frailty could be strongly associated..$^{32}$ Being frail explained one-third of the presence of delirium in participants. In a multiple regression model, including age, cognitive and physical state, polymedication, and comorbidities, $64 \%$ of the variance in delirium could be explained by these variables (adjusted $R^{2}=0.635 ; P \leq 0.001$; Table 5).

No collinearity was found between frailty scores, CAM scores ( $\mathrm{T}-\mathrm{B}$ Kendall $=-0.130$; variance inflation factor $<10$ ), IADL scores $(r=0.44$; variance inflation factor $<10)$, and MMSE scores $(r=0.45$; variance inflation factor $<10){ }^{33}$

\section{Discussion}

Our results indicate that frailty is strongly associated with delirium in older patients as one-fifth of the participants presented delirium at hospital discharge. ${ }^{2}$ Nine of ten delirious participants were frail, whereas only three quarters of the nondelirious participants were frail. These findings are consistent with those of other recent studies indicating an elevated prevalence of frailty among discharged older adults with delirium. ${ }^{34,35}$ However, our study results do not allow to explain this association, and it has recently been mentioned by Teale and Young that the underlying interaction between these two geriatric syndromes is poorly understood. ${ }^{5}$ 
Table 4 Distribution of EFS items in delirious and nondelirious discharged older adults

\begin{tabular}{|c|c|c|c|}
\hline Variables & Delirium & No delirium & $P$-value \\
\hline \multicolumn{4}{|l|}{ Cognitive impairment } \\
\hline No errors & $3(15.0 \%)$ & $19(20.2 \%)$ & \\
\hline Minor errors & $2(10.0 \%)$ & $46(48.9 \%)$ & \\
\hline Major errors & $15(75.0 \%)$ & $29(30.9 \%)$ & $0.00 I^{*}$ \\
\hline \multicolumn{4}{|l|}{ General health } \\
\hline \multicolumn{4}{|c|}{ Number of hospitalizations } \\
\hline 0 & $0(0.0 \%)$ & $18(19.1 \%)$ & \\
\hline $1-2$ & $17(85.0 \%)$ & $68(72.3 \%)$ & \\
\hline$>3$ & $3(15.0 \%)$ & $8(8.5 \%)$ & 0.086 \\
\hline \multicolumn{4}{|c|}{ Autoevaluation of health } \\
\hline Excellent to good & $3(15.0 \%)$ & $20(21.3 \%)$ & \\
\hline Acceptable & $9(45.0 \%)$ & 59 (62.8\%) & \\
\hline Bad & $8(40.0 \%)$ & 15 (I6.0\%) & 0.052 \\
\hline \multicolumn{4}{|c|}{ Functional independence } \\
\hline \multicolumn{4}{|c|}{ IADL dependency score } \\
\hline $0-1$ & I (5.0\%) & $9(9.6 \%)$ & \\
\hline $2-4$ & $4(20.0 \%)$ & $40(42.6 \%)$ & \\
\hline $5-8$ & $15(75.0 \%)$ & 45 (47.9\%) & 0.087 \\
\hline \multicolumn{4}{|c|}{ Social support available } \\
\hline Always & $18(90.0 \%)$ & 79 (84.0\%) & \\
\hline Mostly & $2(10.0 \%)$ & $14(14.9 \%)$ & \\
\hline No support & $0(0.0 \%)$ & I (I.I\%) & 0.755 \\
\hline \multicolumn{4}{|l|}{ Use of five or more } \\
\hline \multicolumn{4}{|l|}{ medications } \\
\hline No & 7 (35.0\%) & $33(35.1 \%)$ & \\
\hline Yes & $13(65.0 \%)$ & $61(64.9 \%)$ & 0.993 \\
\hline \multicolumn{4}{|c|}{ Risks of nonadherence } \\
\hline No & $8(40.0 \%)$ & $64(68.1 \%)$ & \\
\hline Yes & $12(60.0 \%)$ & 30 (31.9\%) & $0.018^{*}$ \\
\hline \multicolumn{4}{|l|}{ Nutrition, weight loss } \\
\hline No & II (55.0\%) & $5 \mathrm{I}(54.3 \%)$ & \\
\hline Yes & $9(45.0 \%)$ & $43(45.7 \%)$ & 0.952 \\
\hline \multicolumn{4}{|c|}{ Mood, sad, or depressed } \\
\hline No & $13(65.0 \%)$ & $57(60.6 \%)$ & \\
\hline Yes & 7 (35.0\%) & 37 (39.4\%) & 0.716 \\
\hline \multicolumn{4}{|l|}{ Incontinence } \\
\hline No & $5(25.0 \%)$ & $57(60.6 \%)$ & \\
\hline Yes & $15(75.0 \%)$ & 37 (39.4\%) & $0.004 *$ \\
\hline \multicolumn{4}{|l|}{ Up and go test } \\
\hline $0-10$ seconds & $7(35.0 \%)$ & 47 (50.0\%) & \\
\hline $\mathrm{II}-20$ seconds & $2(10.0 \%)$ & $22(23.4 \%)$ & \\
\hline$>20$ seconds & II (55.0\%) & $25(26.6 \%)$ & $0.04 I^{*}$ \\
\hline
\end{tabular}

Notes: Pearson's chi-squared test or Fisher's exact test. *Significance $P \leq 0.05$. Abbreviations: EFS, Edmonton Frailty Scale; IADL, Instrumental Activities of Daily Living.

Almost all the participants had some functional impairment, and a third of participants presented a significant cognitive impairment at discharge, which corroborates results from other recent studies. ${ }^{36}$ This highlighted an urgent need for health care owing to a high number of hospitalized older patients presenting several symptoms of frailty. In addition, as already documented elsewhere, discharged older patients face a risk of delirium due to the presence of multifactorial delirium risk factors. ${ }^{37}$ Some studies have observed a strong relationship between delirium and physical decline, as manifested by an elevated number of hospital-related falls. However, the present study was unable to confirm this relationship, as hospital records concerning adverse events during hospitalization, such as falls and other deleterious events, were incomplete..$^{38}$ As in other studies, our results showed no association between age and frailty within the cohort. ${ }^{8}$

In the present study, frailty alone is associated with delirium in more than one-third of cases. In a more complex model - including age, physical and cognitive impairment, polymedication, and polymorbidity - the association of delirium increased, having an impact in up to two-thirds of cases. Thus, cognitive screening alone was more strongly related to delirium than frailty, but cognitive and frailty screening together was even better. These findings confirm that comprehensive geriatric assessment (CGA) and screening for frailty increase early detection of delirium and delirium risks in discharged older adults. Above all, hospitalization itself should be considered as an important delirium and frailty risk factor. Interdisciplinary preventive care strategies focusing on limiting physical and cognitive decline during hospitalization may be effective in averting delirium and frailty and other poor posthospitalization outcomes. ${ }^{39}$ Health care reforms focusing on building more effective and efficient care models for older inpatients are urgently needed to develop "senior-friendly" hospitals, including specialized geriatric care units.

Although the delirium rate among our participants was consistent with other studies, the prevalence of frailty was less easy to compare. ${ }^{35}$ The challenges of detecting delirium in patients after hospital discharge are well described, in contrast to frailty where prevalence is more dependent on the measurement scale..$^{40}$ In the present study, delirium detection and frailty assessment were combined within clinical assessment and routinely collected data; they could be determined for all patients, regardless of their cognitive or functional abilities, thus increasing their potential utility in the clinical setting. The presence of both frailty and delirium confer a particularly poor prognosis, such as dependency, institutionalization, or even premature death. ${ }^{15,41}$ However, as delirium and frailty are both viewed as modifiable geriatric syndromes and given the current trend for moving health care out of the hospital into the home, this raises important questions about patient care management. ${ }^{7}$ Nevertheless, there are links between delirium and frailty. ${ }^{42,43}$ Although frailty is a chronic condition and delirium is a more acute condition, the unavoidable question of a common pathophysiological mechanism persists. Frailty and delirium may be different 
Table 5 Simultaneous multiple regression analysis summary for age, polymedication, frailty, physical and cognitive impairment, and comorbidity

\begin{tabular}{llllll}
\hline Variables & B & SE B & Beta & t & P-value \\
\hline Age & -0.036 & 0.015 & -0.143 & -2.354 & $0.020^{*}$ \\
Polymedication & -0.029 & 0.044 & -0.042 & -0.658 & 0.512 \\
Cognitive impairment (MMSE) & -0.262 & 0.027 & -0.771 & -9.610 & $<0.00 I^{*}$ \\
Delirium (CAM) & -0.052 & 0.414 & -0.003 & -0.903 & 0.396 \\
Frailty (EFS) & 0.193 & 0.045 & 0.309 & 4.324 & -1.097 \\
Physical impairment (IADL) & -0.025 & 0.022 & -0.080 & -0.816 & 0.275 \\
Comorbidity & -0.033 & 0.040 & -0.056 & 0.417 \\
Constant & 11.472 & 1.776 & - & &
\end{tabular}

Notes: Adjusted $R^{2}=0.64 ; F(6,107)=33.81, P \leq 0.001$. *Significant association of delirium.

Abbreviations: SE, standard error; MMSE, Mini-Mental State Examination; CAM, Confusion Assessment Method; EFS, Edmonton Frailty Scale; IADL, Instrumental Activities of Daily Living.

clinical expressions of a shared vulnerability to stress in older adults, and future research should determine whether this vulnerability is age related, pathological, genetic, environmental, or most likely, a combination of all of these factors. ${ }^{44}$ Besides the fact that both syndromes represent significant sources of morbidity and mortality for older adults, both of them are multifactorial, with risk factors and potentially causative mechanisms (eg, inflammation, atherosclerosis, and poor nutrition) that overlap. ${ }^{7}$ Although there are proven measures for preventing delirium, evidence regarding interventions to improve outcomes following delirium remains uncertain. ${ }^{2,39}$ Similarly, while complex interventions such as education, optimized nutrition, and exercise have been suggested for delaying or preventing frailty, there is as yet no evidence that such interventions can mitigate these outcomes in frail older inpatients. ${ }^{45,46}$ Whether multicomponent, nonpharmacological, interdisciplinary interventions are effective in preventing frailty and delirium in hospitalized older adult patients should be the focus of further inquiry. Further research on a larger group of discharged older adults is also required.

Finally, this study has both strengths and limitations. The first strength was the comprehensive geriatric assessment approach used, involving patient records, clinical and CAM assessment after discharge, and optimized delirium detection and frailty assessment. Another strength was that all the participants were accurately screened for their health status and frailty indicators, and they were discriminated by the presence of delirious or nondelirious symptoms.

In addition to the relatively small sample group, it seems important to mention the limiting factor that data were collected at a single hospital site, and thus generalization of these results needs caution. Furthermore, comprehensive geriatric assessment data from the emergency department was incomplete, and therefore we could not make a precise interpretation of participants' mental status at hospital admission. Another limitation of the study concerns the correctional nature of the data. Using the EFS did impose some methodological limits to the study, as the most widely used screening tool to assess frailty is that proposed by Fried et al $^{47}$ This requires the presence of at least three of the five following criteria: weight loss, exhaustion, weak grip strength, slow walking speed, and low physical activity. However, exhausted older inpatients, once discharged, are often unable to complete these performance-based tests, and thus many of the participants in the present study could not have been assessed using such physical testing.

The syndromes of delirium and frailty are highly associated in discharged older adults. However, currently, detecting their delirium remains problematic for several reasons. On the other hand, assessing frailty, either through systematic CGA or by using specific frailty-detection tools, gives health care professionals the opportunity to improve the effectiveness of primary prevention strategies for delirium, by promptly ascertaining which discharged older adults are at a high risk of presenting with that syndrome.

\section{Acknowledgments}

We thank the patients and their families for their participation in this study. This work would not have been possible without the input of Ms Ariane Kapps, a Master of Science student who helped to develop the intervention, as well as that of all the participating nurses of the Home Health Care Service of Valais. The authors also thank Ms Sylvana Gerber for her contribution to successful data collection.

\section{Author contributions}

All authors contributed toward data analysis, drafting and revising the paper and agree to be accountable for all aspects of the work. 


\section{Disclosure}

The authors report no conflicts of interest in this work.

\section{References}

1. American Psychiatric Association. Diagnostic and Statistical Manual of Mental Disorders, Fifth Edition. Washington DC: American Psychiatric Publishing; 2013.

2. Inouye SK, Westendorp RG, Saczynski JS. Delirium in elderly people. Lancet. 2014;383(9920):911-922.

3. Holroyd-Leduc JM, Khandwala F, Sink KM. How can delirium best be prevented and managed in older patients in hospital? CMAJ. 2010; 182(5):465-470.

4. Holt R, Young J, Heseltine D. Effectiveness of a multi-component intervention to reduce delirium incidence in elderly care wards. Age Ageing. 2013;42(6):721-727.

5. Teale EA, Young JR. Multicomponent delirium prevention interventions: not as effective as NICE suggest? Age and Ageing. 2015;44(6): 915-917.

6. McAvay GJ, Van Ness PH, Bogardus ST Jr, et al. Older adults discharged from the hospital with delirium: 1-year outcomes. J Am Geriatr Soc. 2006;54(8):1245-1250.

7. Clegg A, Young J, Iliffe S, Rikkert MO, Rockwood K. Frailty in elderly people. Lancet. 2013;381(9868):752-762.

8. Santangelo A, Testai M, Maugeri D. Delirium is marker of frailty? Study in a population over 90-year old recovered in a Sicilian RSA. Eur Psychiatry. 2010;25:588.

9. Quinlan N, Marcantonio ER, Inouye SK, Gill TM, Kamholz B, Rudolph JL. Vulnerability: the crossroads of frailty and delirium. $J$ Am Geriatr Soc. 2011;59(suppl 2):S262-S268.

10. Abellan Van Kan G, Vellas B. Is the mini nutritional assessment an appropriate tool to assess frailty in older adults? J Nutr Health Aging. 2011;15(3):159-161.

11. Buurman BM, Hoogerduijn JG, van Gemert EA, de Haan RJ, Schuurmans MJ, de Rooij SE. Clinical characteristics and outcomes of hospitalized older patients with distinct risk profiles for functional decline: a prospective cohort study. PLoS One. 2012;7(1):e29621.

12. Clegg A, Young J. The frailty syndrome. Clin Med. 2011;11(1):72-75.

13. Leung JM, Tsai TL, Sands LP. Brief report: preoperative frailty in older surgical patients is associated with early postoperative delirium. Anesth Analg. 2011;112(5):1199-1201.

14. Pol RA, van Leeuwen BL, Visser L, Izaks GJ, van den Dungen JJAM, Tielliu IFJ. Standardised frailty indicator as predictor for postoperative delirium after vascular surgery: a prospective cohort study. Eur J Vasc Endovasc Surg. 2011;42(6):824-830.

15. Leung JM, Tsai TL, Sands LP. Preoperative frailty in older surgical patients is associated with early postoperative delirium. Anesth Analg. 2011;112(5):1199-1201.

16. Verloo H, Goulet C, Morin D, von Gunten A. Effect estimation of an innovative nursing intervention to improve delirium among homedwelling older adults: a randomized controlled pilot trial. Dement Geriatr Cogn Dis Extra. 2015;5(1):176-190.

17. Folstein MF, Folstein SE, McHugh PR. "Mini-mental state". A practical method for grading the cognitive state of patients for the clinician. J Psychiatr Res. 1975;12(3):189-198.

18. Laplante J, Cole MG, McCusker J, Singh S, Ouimet MA. Confusion assessment method. Validation of a French-language version. Perspect Infirm. 2005;3(1):12-20.

19. Wei LA, Fearing MA, Sternberg EJ, Inouye SK. The confusion assessment method: a systematic review of current usage. J Am Geriatr Soc. 2008;56(5):823-830.

20. Hair JKJ, Black WC, Babin BJ, Anderson RE. Multivariate Data Analysis: A Global Perspective. 7th ed. Boston: Pearson Education Inc; 2010.

21. Rolfson DB, Majumdar SR, Tsuyuki RT, Tahir A, Rockwood K. Validity and reliability of the Edmonton Frail Scale. Age Ageing. 2006; 6:526-529.
22. de Vries NM, Staal JB, van Ravensberg CD, Hobbelen JSM, Olde Rikkert MGM, Nijhuis-van der Sanden MWG. Outcome instruments to measure frailty: a systematic review. Ageing Res Rev. 2011; 10(1):104-114.

23. Podsiadlo D, Richardson S. The timed up \& go: a test of basic functional mobility for frail elderly persons. J Am Geriatr Soc. 1991;39:142-148.

24. Derouesné C, Poitreneau J, Hugonot L, Kalafat M, Dubois B, Laurent B. Le mini-mental state examination (MMSE): un outil pratique pour l'évaluation de l'état cognitif des patients par le clinicien, version française consensuelle. [Mini mental state Exam: a practical tool for clinicians to assess the cognitive state of patients, French consensual version]. La Presse Médicale. 1999;28(21):1141-1148. French.

25. Naugle RI, Kawczak K. Limitations of the mini-mental state examination. Cleve Clin J Med. 1989;56(3):277-281.

26. Lawton MP, Brody EM. Assessment of older people: self-maintaining and instrumental activities of daily living. Gerontologist. 1969;9(3): 179-186.

27. Buurman BM, van Munster BC, Korevaar JC, de Haan RJ, de Rooij SE. Variability in measuring (instrumental) activities of daily living functioning and functional decline in hospitalized older medical patients: a systematic review. J Clin Epidemiol. 2011;64(6):619-627.

28. Barberger-Gateau P, Commenges D, Gagnon M, Letenneur L, Sauvel C, Dartigues JF. Instrumental activities of daily living as a screening tool for cognitive impairment and dementia in elderly community dwellers. J Am Geriatr Soc. 1992;40(11):1129-1134.

29. Miller MD, Paradis CF, Houck PR, et al. Rating chronic medical illness burden in geropsychiatric practice and research: application of the Cumulative Illness Rating Scale. Psychiatry Res. 1992;41(3): 237-248.

30. Tabachnick BG, Fidell LS. Using Multivariate Statistics. 6th ed. Boston: Pearson Education Inc; 2013.

31. IBM-SPSS. Statistical Package for Social Sciences. Somer, NY: IBM Corporation; 2011.

32. Cohen J. Statistical Power and Analysis for the Behavioral Sciences. 2nd ed. Hillsdale, NY: Lawrence ERdbaum Associates; 1988.

33. Mason CH, Perreault WD Jr. Collinearity, power, and interpretation of multiple regression analysis. J Market Res. 1991;28(3):268-280.

34. Eeles EMP, Peel NM, White SV, O'Mahony MS, Bayer AJ, Bhat R. Frailty and illness severity in relation to delirium in older inpatients. Australas J Ageing. 2013;32:28.

35. Joosten E, Demuynck M, Detroyer E, Milisen K. Prevalence of frailty and its ability to predict in hospital delirium, falls, and 6-month mortality in hospitalized older patients. BMC Geriatr. 2014;14:1.

36. Hoogerduijn JG, Buurman BM, Korevaar JC, Grobbee DE, de Rooij SE, Schuurmans MJ. The prediction of functional decline in older hospitalised patients. Age Ageing. 2012;41(3):381-387.

37. Covinsky KE, Pierluissi E, Johnston CB. Hospitalization-associated disability: "she was probably able to ambulate, but I'm not sure". J Am Med Assoc. 2011;306(11):1782-1793.

38. Witlox J, Eurelings LSM, de Jonghe JFM, Kalisvaart KJ, Eikelenboom P, van Gool WA. Delirium in elderly patients and the risk of postdischarge mortality, institutionalization, and dementia: a meta-analysis. $J \mathrm{Am} \mathrm{Med}$ Assoc. 2010;304(4):443-451.

39. Cameron I, Fairhall N, Gill L, Lockwood K, Langron C, Aggar C. Developing interventions of frailty. Adv Geriatr. 2015;2015:845356.

40. Clegg A, Westby M, Young JB. Under-reporting of delirium in the NHS. Age Ageing. 2011;40(2):283-286.

41. Eeles EMP, White SV, O'Mahony SM, Bayer AJ, Hubbard RE. The impact of frailty and delirium on mortality in older inpatients. Age Ageing. 2012;41(3):412-416.

42. Andrew MK. Le capital social et la santé des personnes âgées. [Social capital and healthy aging]. Retraite et Société. 2005;46:132-145. French.

43. Agostini JV, Zhang Y, Inouye SK. Use of a computer-based reminder to improve sedative-hypnotic prescribing in older hospitalized patients. J Am Geriatr Soc. 2007;55(1):43-48. 
44. Bergman H, Ferrucci L, Guralnik JM, Hogan DB, Hummel S, Karunananthan S. Frailty: an emerging research and clinical paradigm issues and controversies. J Gerontol A Biol Sci Med Sci. 2007;62(7) 731-737.

45. Oo MT, Tencheva A, Khalid N, Chan YP, Ho SF. Assessing frailty in the acute medical admission of elderly patients. $J R$ Coll Physicians Edinb. 2013;43(4):301-308.
46. Turner G, Clegg A. Best practice guidelines for the management of frailty: a British Geriatrics Society, age UK and Royal College of General Practitioners report. Age Ageing. 2014;43(6):744-747.

47. Fried LP, Tangen CM, Walston J, Newman AB, Hirsch C, Gottdiener J. Frailty in older adults: evidence for a phenotype. J Gerontol A Biol Sci Med Sci. 2001;56(3):M146-M156.

\section{Publish your work in this journal}

Clinical Interventions in Aging is an international, peer-reviewed journal focusing on evidence-based reports on the value or lack thereof of treatments intended to prevent or delay the onset of maladaptive correlates of aging in human beings. This journal is indexed on PubMed Central, MedLine,

\section{Dovepress}

CAS, Scopus and the Elsevier Bibliographic databases. The manuscript management system is completely online and includes a very quick and fair peer-review system, which is all easy to use. Visit http://www.dovepress. $\mathrm{com} /$ testimonials.php to read real quotes from published authors. 